\title{
Vibration Analysis of Turbine Rotor System
}

\author{
Xiaoyun $\mathrm{Li}^{1}$, Yijui Chiu ${ }^{1, \mathrm{a}^{*}}$, Keke Sun ${ }^{2, \mathrm{~b}}$, Shengbo $\mathrm{Li}^{1 \mathrm{c}}$ and Dongsheng $\mathrm{Lin}^{1}$ \\ ${ }^{1}$ School of Mechanical and Automotive Engineering, Xiamen University of Technology, No. 600, \\ Ligong Rd, Xiamen, 361024, Fujian Province, China. \\ ${ }^{2}$ School of Design Arts and Fashion Design, Xiamen University of Technology, No. 600, Ligong Rd, \\ Xiamen, 361024, Fujian Province,China. \\ achiuyijui@xmut.edu.cn, bsunkeke@xmut.edu.cn, chit4057@xmut.edu.cn \\ * The Corresponding author
}

Keywords: Engine; Turbocharger; Rotor dynamics

\begin{abstract}
The design and the modal analysis of a small turbocharger rotor system are carried out in this paper. The design process and method of rotor system are summarized. Some useful conclusions are obtained in the modal analysis. These results will provide engineers with valuable information about the vibration characteristics of the turbine rotor system and the design of the rotor system.
\end{abstract}

\section{Introduction}

The vehicle engine began to widely used turbo charging technology. Turbocharger is the use of rotor rotation compression to improve the air pressure in the cylinder, increasing the combustion efficiency of the engine, so not only achieved the purpose of reducing the loss of resources, but also increase the engine power, vehicle overall fuel consumption. The rotor system is the most important component in a turbocharged engine, so the vibration of the rotor system and the number of rotations of the rotor system greatly affect the performance of the engine with turbocharged. The researches are in this field, such as Jung and Krumdieck [1] analyzed the rotor dynamics of a $1 \mathrm{KWe}$ radial flow turbine rotor bearing system. Modal and mass unbalance responses are analyzed for six cases with different shaft diameters and bearing configurations. They select the best conditions for further parameters to study the effect of shaft length, blade residual unbalance and bearing stiffness on the blade displacement amplitude. Samoilenk and Cho [2] based on the experimental data. They explored effects of vaneless turbocharger on combustion efficiency and emission characteristics of diesel engine. Danish and Qureshi [3] presented extensive numerical studies on the performance and flow structure of a tandem centrifugal compressor without hood. Typically, the performance of a centrifugal compressor without tandem blades performs better at moderate flow rates. Near throttling flow, tandem design gives better results. The main reason is that the throat area increases and the surge point flow of the compressor is also decreased, which the results increase operating range. Koutsovasilis et. al. [4] developed a method for the study of a turbocharger with full floating ring bearings. It allows quantitative, sub synchronous vibration during startup simulation. It is carried out by considering the input parameters of the wheel shaft and bearing geometry. The changes are related to amplitude and duration criteria to quantify the effects of sub synchronous evolution.

The authors [5-6] used assumed mode method (AMM) and the finite element method (FEM) to investigate a single/multi flexible disk system with lacing wires. The modal analysis of a small turbocharger rotor system are carried out in this paper

\section{Theories Analysis}

The model of this paper is designed through CATIA 3D modeling software. A three-dimensional model of turbocharger rotor bearing system is built. The advantage of CATIA is that could compare simple 
design curved surface and had good usability and high efficiency. Fig. 1 shows the model of turbine rotor system. The compressor impeller is on the left and the turbine impeller is on the right.

The material of the compressor impeller is aluminum alloy. The material of the turbine is chosen as K418 nickel based cast alloy. , The material of the shaft is $42 \mathrm{CrMo}$. The material coefficients of the turbocharger rotor are shown in table 1 . Table 2 presents the parameters of the turbocharger rotor system.

Table 1. The material coefficients of the turbocharger rotor

\begin{tabular}{cccc}
\hline & Young Modulus $(\mathrm{GPa})$ & Density $\left(\mathrm{kg} / \mathrm{m}^{3}\right)$ & Poisson ratio \\
\hline Compressor impeller & 72 & 2680 & 0.33 \\
\hline Turbine impeller & 176 & 8000 & 0.3 \\
\hline shaft & 210 & 7820 & 0.3 \\
\hline
\end{tabular}

Table 2. The parameters of the turbocharger rotor system

\begin{tabular}{cccccc}
\hline & $\begin{array}{c}\text { Blade } \\
\text { number }\end{array}$ & $\begin{array}{c}\text { Maximum } \\
\text { diameter }(\mathrm{mm})\end{array}$ & $\begin{array}{c}\text { Hub diameter } \\
(\mathrm{mm})\end{array}$ & $\begin{array}{c}\text { Air flow } \\
\text { angle }\left({ }^{\circ}\right)\end{array}$ & $\begin{array}{c}\text { Length } \\
(\mathrm{mm})\end{array}$ \\
\hline $\begin{array}{c}\text { Turbine } \\
\text { impeller }\end{array}$ & 11 & 64 & 16 & 22.2 & 1 \\
\hline $\begin{array}{c}\text { Compressor } \\
\text { impeller }\end{array}$ & 10 & 66 & 13 & 17.7 & 1 \\
\hline Shaft & 1 & 1 & 1 & 1 & 173 \\
\hline
\end{tabular}

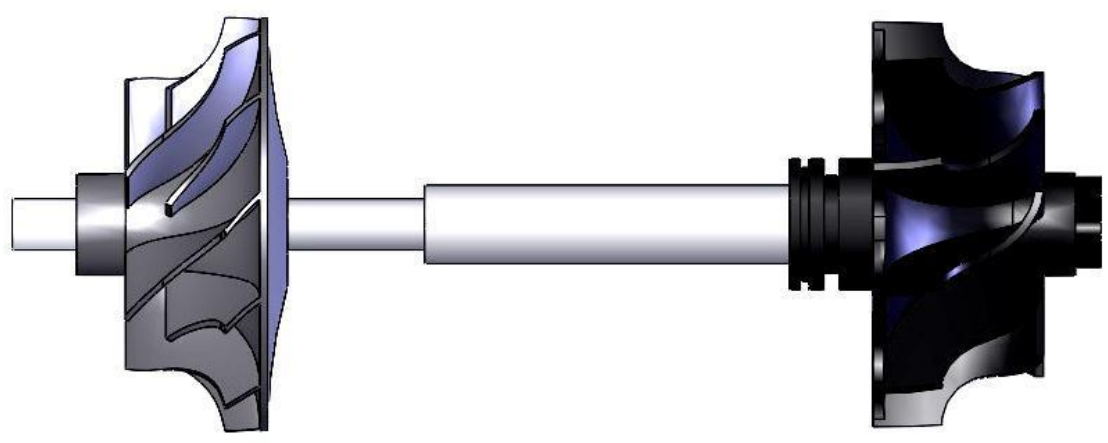

Fig. 1. The model of turbine rotor system

Because the structure of body structure of turbine rotor system was very complex, we should simplify the structure first. This paper exports the equations of the system.

$$
[M]\{\ddot{X}\}+[K]\{X\}=0
$$

Defined the position vector $\{X\}$ as $[\Delta]\{u\}$, where $[\Delta]$ was the modal matrix of the system. Eq. (1) could be changed as follow:

$$
[I]\{\ddot{u}\}+[A]\{u\}=0
$$

In which:

$$
[\Delta]^{T}[M][\Delta]=[I]=\left[\begin{array}{cccc}
1 & 0 & \cdots & 0 \\
0 & 1 & \cdots & \vdots \\
\vdots & 0 & \ddots & 0 \\
0 & 0 & 0 & 1
\end{array}\right]
$$


$[\Delta]^{T}[K][\Delta]=[A]=\left[\begin{array}{cccc}\bar{\omega}_{1}^{2} & 0 & \cdots & 0 \\ 0 & \bar{\omega}_{2}^{2} & \cdots & \vdots \\ \vdots & 0 & \ddots & 0 \\ 0 & \cdots & 0 & {\frac{\omega_{n}}{2}}^{2}\end{array}\right]$

The natural frequency of the mistuned system was expressed as follow:

$$
\overline{\omega_{n}}=\frac{\omega_{n}}{\sqrt{\frac{E I}{\rho A L^{4}}}}, n=1,2,3 \ldots \ldots
$$

\section{Dynamic Analysis}

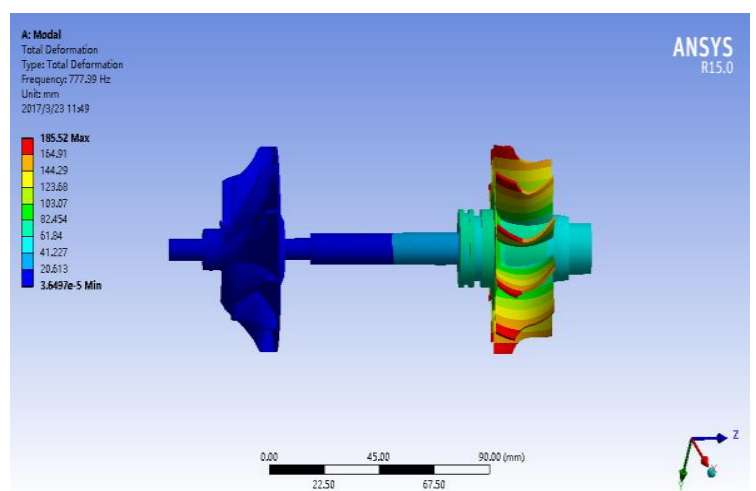

(a) $1 \mathrm{st}$

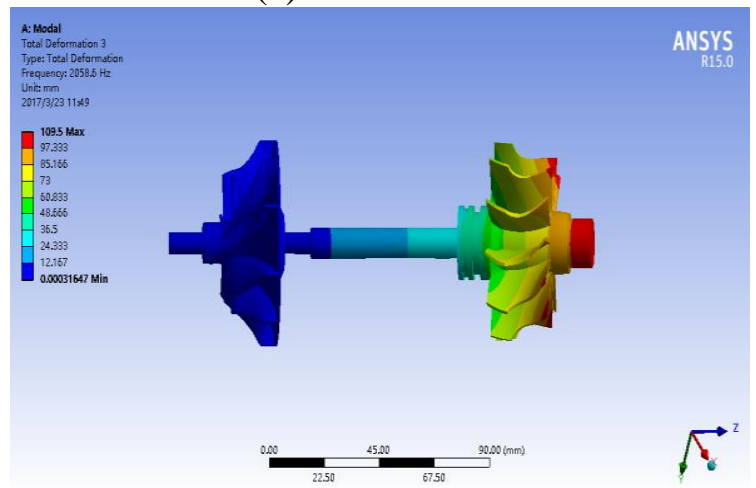

(c) $3 \mathrm{rd}$

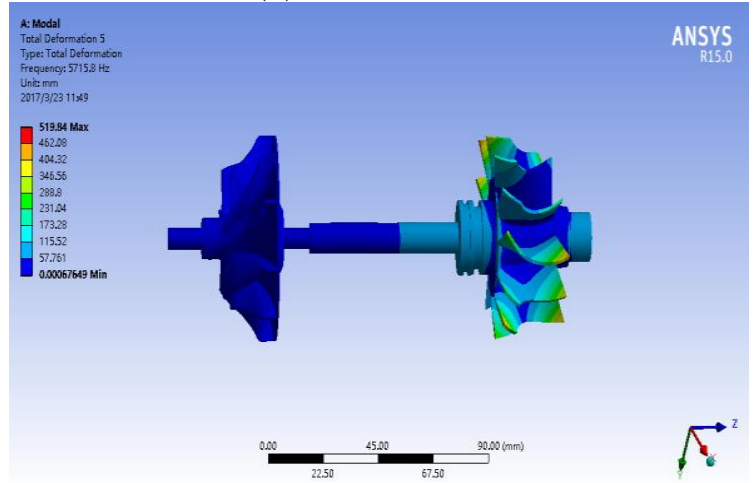

(e) 5 th

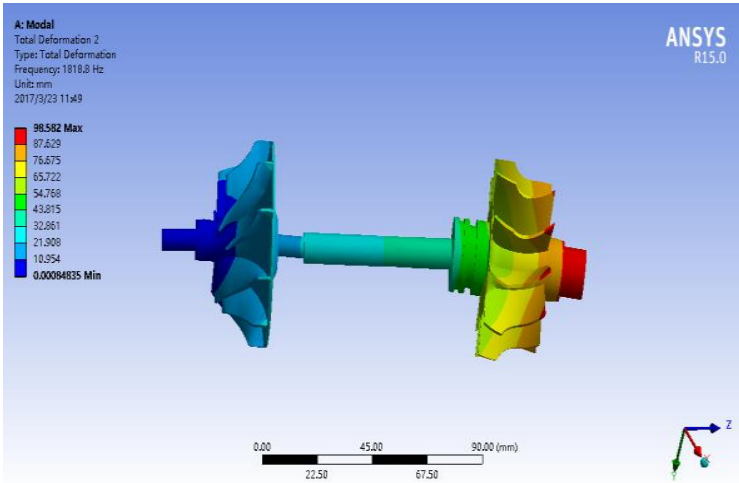

(b)2nd

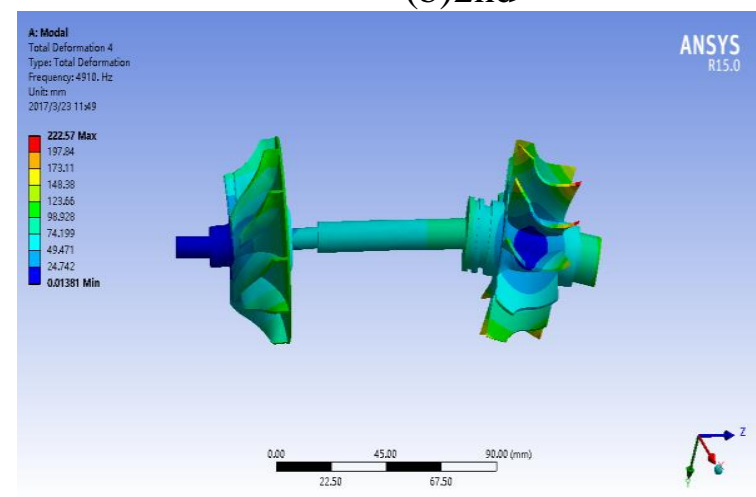

(d) 4 th

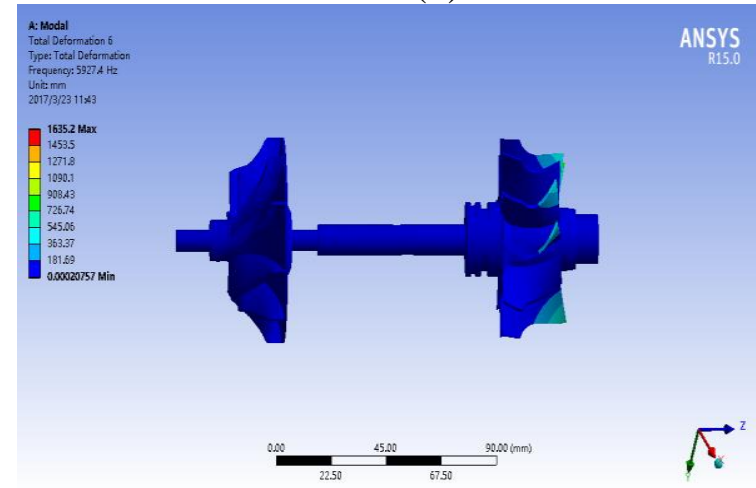

(f)6th 


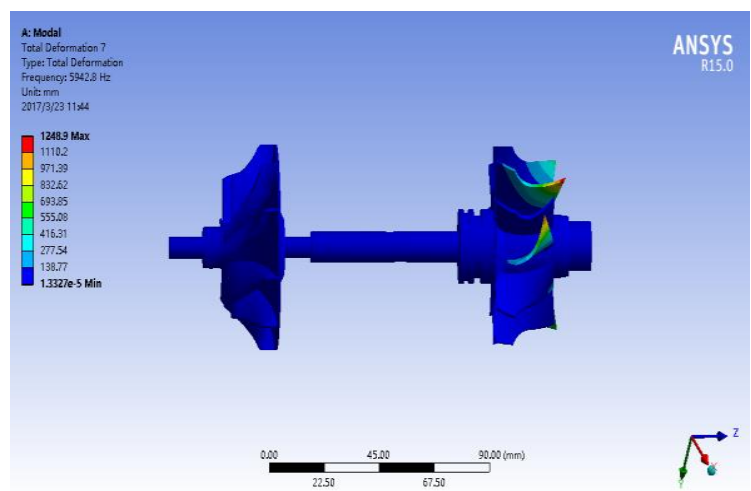

(g) 7 th

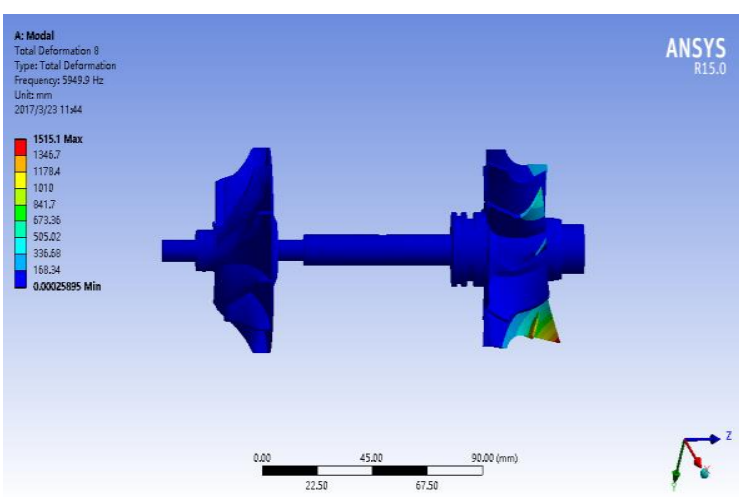

(h) 8 th

Fig. 2. The first ten mode shapes of turbine rotor system.

Table 3 shows the first ten natural Frequencies $(\mathrm{Hz})$ of turbine rotor system. Fig. 2 shows the first ten mode shapes of turbine rotor system.

Table 3. The first ten natural Frequencies $(\mathrm{Hz})$ of turbine rotor system

\begin{tabular}{ccccccccccc}
\hline Order & 1 & 2 & 3 & 4 & 5 & 6 & 7 & 8 & 9 & 10 \\
\hline $\begin{array}{c}\text { Frequenc } \\
\mathrm{y}\end{array}$ & 777.39 & 1818.8 & 2058.6 & 4910.0 & 5715.8 & 5927.4 & 5942.8 & 5949.9 & 5956.3 & 5961.9 \\
\hline
\end{tabular}

Fig.2(a) shows the first modes exhibit the first order torsional modes and the directions are horizontal. Fig.2(b) and 2(c) show the first bending modes, respectively, in horizontal and vertical directions. Fig.2 (d) and 2(e) show second bending mode. Fig.2 (f) to 2(h) show the mode of vibration is the twist of turbine blade. The authors consider factors such as chamfering that lead to an increase in blade thickness, which leads to an increase in natural frequency. Therefore, the actual natural frequency value should be higher than the natural frequency value shown in table 3 .

The maximum deformation occurs in the first order mode and the lowest vibration frequency. Therefore, we should try to shorten the time of this vibration frequency in the actual application process.

\section{Conclusion}

The rotor system of a small turbocharger is designed. The structures, the size design of the turbine and compressor impeller are calculated in this paper. The authors carried out the modal analysis of the dynamic characteristics of the turbocharger rotor system. The natural frequencies and mode shapes of the first ten orders are obtained. The maximum deformation occurs in the first order mode and the lowest vibration frequency. Therefore, we should try to shorten the time of this vibration frequency in the actual application process.

\section{Acknowledgements}

This study is sustained by Fujian Nature Project No. 2016J01039 and 2015J01228, Xiamen City Project No. $3502 Z 20173037$

\section{References}

[1] Jung H.C. and Krumdieck S. (2014) Rotordynamic modelling and analysis of a radial inflow turbine rotor-bearing system.International Journal of Precision Engineering and Manufacturin. 15(11), pp. 2285-2290.

[2] Samoilenk D. and CHO M. (2013), Improvement of combustion efficiency and emission characteristics of diesel engine operating on ESC cycle applying variable geometry turbocharger with vaneless turbine volutd. International Journal of Automotive Technology, 14(4), pp. 521-528 
[3] Danish S.N., Qureshi S.R., Leathy A.,Khan S.D., Umer U., Ma C.C. (2014), Numerical investigation and comparison of a tandem-bladed turbocharger centrifugal compressor stage with conventional design[J]. Journal of Thermal Science 23(6), pp. 523-534 .

[4] Koutsovasilis P., Driot N., Lu D.X. and Schweizer B. (2015), Quantification of sub-synchronous vibrations for turbocharger rotors with full-floating ring bearings.Arch Appl Mech, 85, pp.481-502.

[5] Zhou S.T., Chiu Y.J., Yu G.F., Yang C.H., Huang H.W., Jian S.R., (2017), An assumed mode method and finite element method investigation of the coupled vibration in a flexible-disk rotor system with lacing wires. Journal of Mechanical Science and Technology, 31(2), pp. 577-586.

[6] Chiu Y.J., Jian S.R., Yang C.H., Yu G.F., (2017), Based on lacing wires influence of coupling vibration of a multi flexible disks turbine rotor system by two methods. Journal of Vibroengineering, 19(2), 1314-1331. 